\title{
E-cigarettes-The latest issues
}

\author{
Sankalp Yadav 1,", Gautam Rawal ${ }^{2}$ \\ ${ }^{1}$ General Duty Medical Officer II, Dept. of Medicine \& TB, Chest Clinic, Moti Nagar, North Delhi Municipal Corporation, New \\ Delhi, ${ }^{2}$ Associate Consultant, Respiratory Intensive Care, Max Super Specialty Hospital, New Delhi, India
}

*Corresponding Author:

Email: drsankalpyadav@gmail.com

The conventional tobacco smoking is widely reported as harmful to health due to the presence of nicotine and its nitrosamine derivatives, containing numerous $(>7,000)$ incomplete combustion byproducts, such as polycyclic aromatic hydrocarbons, aromatic amines, aldehydes, and benzene, many of which are human carcinogens, irritants, and allergens [1,2]. The development of electronic cigarettes (e-cigarettes, ecigs, vapes, and electronic nicotine delivery systems [ENDS]) post-2003 as an alternative to the regular cigarette in order to curb the harmful effects of smoking was a revolutionary step [3]. The extensive marketing and large-scale consumption backed by heavy monetary inputs by the well-known tobacco companies has created a greater interest in the pros and cons associated with this relatively new smoking substitute [4]. A number of studies both in the animal and humans have suggested that the vaporized nicotine and other substances arising due to e-cigarettes smoke are harmful [3]. The US surgeon general has given clear advice on the issues associated with this type of smoking, yet there are no/few regulatory bodies for controlling the sales and marketing of it [5]. Besides, due to the paucity of the large-scale studies comparing the impact of it on the health of its consumer with respect to the effects of the regular cigarette smoking is also lacking [4].

As per the WHO, there were more than 450 brands of various types of e-cigarettes in the year $2014[4,6]$. Thus, clearly indicating the big market and heavy consumption of e-cigarettes. The WHO also expected that the total sales would increase to nearly 17 fold by the year 2030 [6]. The majority of consumers falling in the age group of 30-50 years with an ever-growing number of adolescents as well $[7,8]$.

The main component of e-cigarette i.e., the vaporized solutions, or e-liquids, is made up of various proportions of vegetable glycerin, water, propylene glycol, nicotine solution, and flavoring agents [9]. The byproducts of these include carcinogens or irritants like carbonyl compounds, formaldehyde, acetaldehyde, acetone, and butanal. The flavoring agents of ecigarettes generate diacetyl, 2,3-pentandedione, and acetoin [4]. These can cause respiratory damage (i.e., bronchiolitis obliterans) [4]. In another study, heavy metals (tin, silver, iron, nickel, and aluminum), silicate beads, and nanoparticles were detected [4]. All of these byproducts of e-cigarettes are included in the FDA's database of harmful and potentially harmful chemicals [4]. One study reported that the smoke from e-cigarettes cause DNA damage in mouse lung, bladder, and heart and impairs DNA-repair functions and proteins in the lungs [10]. The same effects including enhanced mutations and tumorigenic cell transformation in cultured human lung and bladder cells are also reported [10]. E-cigarettes can also lead to cardiac events and arrhythmias in persons with or at risk for cardiac disease as it can increase the heart rate and blood pressure [11].

The higher popularity of e-cigarette is due to its effect on both the physical (i.e. nicotine) and the behavioral aspect of smoking [12]. E-cigarettes are unique in that they provide rituals associated with smoking behavior (e.g. hand-to-mouth movement, visible 'smoke' exhaled) and sensory stimulation associated with it are some of the features that are generally absent in nicotine replacement therapies (NRTs) and oral medications for nicotine dependence [12].

To sum up, the awareness and use of e-cigarettes are growing exponentially [12]. The major contributor to it is the belief that it's a healthy substitute for the conventional smoking [12]. Although, studies have reported that the e-cigarettes reduce the smoking addiction, yet there are no large-scale studies to prove so [4]. A limited amount of data is available which cannot be accepted as universal evidence against or in favor of the e-cigarettes. There is clear evidence that the total amount of harmful substances arising of ecigarettes are less than that arising from smoking regular cigarettes, yet the effects of these byproducts on the overall health of the smoker need to be studied in detail. Large-scale population-based studies to study the benefits and adverse effects of this relatively new habit are imperative.

Conflicts of interests: None declared Acknowledgements: None

\section{References:}

1. Hecht SS. Tobacco smoke carcinogens and lung cancer. $J$ Natl Cancer Inst 1999;91:1194-210.

2. NTP (National Toxicology Program) (2016) Report on carcinogens, 14th Edition (US Department of Health and Human Services, Public Health Service, Research Triangle Park, NC). Available from URL:- 
http://ntp.niehs.nih.gov/go/roc14. Accessed September 1, 2018.

3. Fagerstrom K, Etter J, Unger J. E-Cigarettes: a disruptive technology that revolutionizes our field? Nicotine Tob Res 2015;17:125-26.

4. Lee R. Current issues regarding e-cigarettes. Available from URL:- https://ajp.psychiatryonline.or g/doi/full/10.1176/appi.ajp-rj.2016.111004\#pane-pcwrelated. Accessed September 1, 2018.

5. The facts on e-cigarette use among youth and young adults. Available from URL:- https://e-

cigarettes.surgeongeneral.gov/. Accessed September 1, 2018.

6. World Health Organization. Electronic nicotine delivery systems. Geneva, Switzerland, 2014. Available from URL:-

http://apps.who.int/gb/fctc/PDF/cop6/FCTC_COP6_10Re v1-en.pdf?ua=1. Accessed September 1, 2018.

7. Rahman M, Hann N, Wilson A, Worrall-Carter L. Electronic cigarettes: patterns of use, health effects, use in smoking cessation and regulatory issues. Tob Induc Dis 2014;12:21:1-9.

8. Centers for Disease Control and Prevention: E-cigarette use triples among middle and high school students in just one year. Atlanta, CDC, 2015. Available from URL:http://www.cdc.gov/media/releases/2015/p0416-ecigarette-use.html. Accessed September 1, 2018.

9. Kosmider L, Sobczak A, Fik M, Knysak J, Zaciera M, Kurek J, et al. Carbonyl compounds in electronic cigarette vapors: effects of nicotine solvent and battery output voltage. Nicotine Tob Res 2014;16:1319-326.

10. Hyun-Wook L, Sung-Hyun P, Mao-wen W, Hsiang-Tsui W, Huang WC, Herbert L, et al. E-cigarette smoke damages DNA and reduces repair activity in mouse lung, heart, and bladder as well as in human lung and bladder cells. Proceedings Natl Acad Sci 2018:201718 185.

11. Lippi G, Favaloro EJ, Meschi T, Mattiuzzi C, Borghi L, Cervellin G. E-cigarettes and cardiovascular risk: beyond science and mysticism. Semin Thromb Hemost 2014;40:60-65.

12. Farsalinos KE, Polosa R. Safety evaluation and risk assessment of electronic cigarettes as tobacco cigarette substitutes: a systematic review. Ther Adv Drug Saf 2014;(2):67-86.

How to cite this article: Yadav S., Rawal G. Ecigarettes-The latest issues. IP Indian J Immunol Respiratory Med 2018;3(3):92-93. 